cal considerations: more or less weight must be given to different results on other than purely mathematical grounds; hence identical final results would not always be arrived at by different calculators starting from the same experimental data. Inasmuch as "the atomic weight of each element involves the probable error of all the other elements to which it is directly or indirectly referred," it may happen that the probable error attaching to an atomic weight determination is large, although the experimental data are extremely accurate. Thus, Crookes, by very accurate experiments, found the atomic weight of thallium to be 203.642 ; but this number supposes that $\mathrm{NO}_{3}=6 \mathrm{I} .889$; the value to be now assigned to the atomic weight of thallium depends on the accuracy with which the atomic weights of oxygen and nitrogen have been determined. The work of Crookes simply fixes, with great accuracy, the ratio between the equivalents of $\mathrm{Tl}$ and $\mathrm{NO}_{3}$.

The most probable value for the atomic weight of oxygen is found to be $15^{\circ} 9633(\mathrm{H}=\mathrm{I})$, with a probable error of $\pm{ }^{\circ} 0035$; any error which there may be in this determination is involved in the determinations of the atomic weights of most of those elements which come after oxygen. When the atomic weight is large, the error thus introduced may be considerable : thus if $\mathrm{O}=15^{\circ} 9633$ $\mathrm{Ur}=238^{\circ} 482$, but if $\mathrm{O}=16^{\circ} \mathrm{Oo} \mathrm{Ur}=239^{\circ} \mathrm{O} 3$; difference $=0.548$.

Some of the weighings involved in the calculations have been reduced to absolute standards, others are only uncorrected weighings in air ; hence an error is sometimes introduced which cannot be eliminated.

The discovery of Dumas that silver prepared by the method of Stas, occludes weighable quantities of oxygen, has been already referred to ; in four experiments Dumas found that I kilogram of silver occluded $82,226,140$, and 249 milligrams of oxygen respectively; the largest of these numbers is taken by Prof. Clarke as "Dumas' correction." The effect of applying this correction is generally very slightly to lower the value of the atomic weight; the following table exhibits this effect in a few instances :-

\begin{tabular}{|c|c|c|c|c|c|c|}
\hline & & Uncorrected. & & Corrected. & & Difference \\
\hline Silver & $\cdots$ & 107.923 & $\cdots$ & $107 \cdot 896$ & $\cdots$ & -.027 \\
\hline ine & $\ldots$ & $35^{\circ} 45 \mathrm{I}$ & $\ldots$ & $35^{\circ} 47^{8}$ & $\ldots$ & +027 \\
\hline Bro & $\ldots$ & $79^{\circ} 751$ & $\ldots$ & 79.978 & $\ldots$ & +.027 \\
\hline ... & $\ldots$ & 126.848 & $\ldots$ & 126.875 & & +027 \\
\hline otassium & $\cdots$ & $39^{\prime} 109$ & $\ldots$ & $39^{\circ} 08$ & & -.026 \\
\hline odium & $\ldots$ & $23^{\circ} 05^{I}$ & $\ldots$ & $23^{\circ} \mathrm{O} 24$ & $\ldots$ & -.027 \\
\hline
\end{tabular}

In the appendix is given a table containing the mean atomic weights (with probable errors attiched) for all the elements, calculated from the most trustworthy data. It is shown that twenty-five out of the sixty-six elements considered have atomic weights the values of which differ by less than one-tenth of a unit from whole numbers, $(\mathrm{H}=\mathrm{I}$ ) but many of those numbers which differ by more than this fraction involve any error which there may be in the determination of the value of the atomic weight of oxygen, multiplied many times. If the possible error in the value for oxygen be transferred to that for hydrogen, i.e. of $\mathrm{O}=16$, then it is shown that forty-four out of the sixty-six elements have atomic weights differing by less than one-tenth of a unit from whole numbers. Of these forty-four elements, twenty-six show plus, and thirteen minus variations from whole numbers. Those which exhibit minus variations are discussed in detail; the values for the atomic weights of seven of these have not been determined with any great accuracy; silver alone has a value which carries "very much weight against the hypothesis of Prout." Cf those elements, twenty-six in number, the atomic weigirts of which exhibit plus variations (less than $O^{\prime} I$ ) from whole numbers, three-viz. $\mathrm{Nb}, \mathrm{Yt}$, and $\mathrm{Ur}$--have values which have been very inaccurately determined; seven involve "Dumas' correction," the application of which will bring the values nearer whole numbers ( $\mathrm{Al}, \mathrm{As}, \mathrm{Ba}, \mathrm{Cd}, \mathrm{Li}, \mathrm{P}$, and $\mathrm{Na}$ ). Special sources of possible error are indicated in the discussion of the atomic weights of $\mathrm{Al}, \mathrm{Ca}, \mathrm{F}$. Five, of the twenty-six elements, have atomic weights the values of which involve errors due to the possible occlusion of hydrogen by the metals when reduced from their compounds ( $\mathrm{Co}, \mathrm{Fe}, \mathrm{Ir}, \mathrm{Ni}$, and $\mathrm{W})$. In many other cases the variations from whole numbers are extremely small, i.e. much less than one-tenth of a unit. "In short in the majority of instances the errors may be diminished by corrections which are in all probability needed, and which we can easily point out."

Twenty-six elements have atomic weights the values of which vary more than one-tenth of a unit from whole numbers; of these twenty-six, three-viz. $\mathrm{Cl}, \mathrm{Rb}$, and $\mathrm{Sr}$ have values nearly half multiples of that of hydrogen; the atomic weights of nine-viz. $\mathrm{Sr}, \mathrm{Au}, \mathrm{In}, \mathrm{La}, \mathrm{Rh}, \mathrm{Ru}$, $\mathrm{Si}, \mathrm{Te}$, and $\mathrm{Zr}-$ have been very imperfectly determined; the atomic weights of $\mathrm{Sb}, \mathrm{Ce}, \mathrm{Be}, \mathrm{Yt}, \mathrm{Pt}$, and $\mathrm{Hg}$ are discussed, and it is shown that the atomic weights of these elements may come within Prout's hypothesis; no criticism is offered on the atomic weights of $\mathrm{Cr}(52 \cdot 129 \pm$

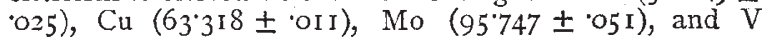
$(51 \cdot 373 \pm \cdot 024)$.

The value to be assigned to iodine (126:848 \pm 022) depends on that for silver; at present iodine stands as an important exception to Prout's rule. Potassium presents a serious objection ; but if "Dumas' correction" is applied $\mathrm{K}$ becomes $39^{\circ} \mathrm{O} 83[\mathrm{O}=\mathrm{r} 6]$. Clarke concludes by saying that although he began his examination of atomic weights strongly prejudiced against Prout's hypothesis, the facts have obliged him to give it "a very respectful consideration." "All chemists must at least admit that the strife over it is not yet ended, and that its opponents cannot thus far claim a perfect victory."

The recalculation of atomic weights shows clearly to the chemist what experimental work ought now to be undertaken; revisions of the atomic weights of tellurium, silicon, boron, mercury, chromium, manganese, uranium, and gold are urgently called for. The "periodic law" requires that the atomic weight of tellurium should be smaller than that of iodine; although the mean number recently obtained by Wills is greater than 127 , yet this number cannot be accepted as final. Several results brought out by Clarke have an important bearing on the "periodic law." In most of the tables of elements arranged in accordance with the law, didymium is placed before cerium and lanthanum; Clarke however shows that $\mathrm{Di}=144.573( \pm .03 \mathrm{I}) ; \mathrm{Ce}=140^{\circ} 424\left( \pm{ }^{\circ} \mathrm{OI} 7\right)$; and $\mathrm{La}=138.526( \pm .03)$. Brauner, in his paper recently published in Chem. Soc. Journal, finds Di $=146.18$ (mean of three results), and $\mathrm{La}=139.58$ (mean of two results). We may therefore conclude that $\mathrm{La}<\mathrm{Ce}<\mathrm{Di}$. These elements then come in series 8 ; lanthanum in group III. giving the characteristic oxide $\mathrm{La}_{2} \mathrm{O}_{3}$, cerium in group IV. giving the oxide $\mathrm{Ce}_{2} \mathrm{O}_{4}$, and didymium in group $\mathrm{V}$. with the oxide $\mathrm{Di}_{2} \mathrm{O}_{5}$, which oxide has been lately prepared and examined by Brauner (Chem. Soc. Jnl. Trans., 1882, p. 68).

Prof. Clarke's work may be taken as a type of what is now so much wanted in chemistry : a careful collection and digestion of masses of facts. We seem to be forgetting that chemistry is a science, not a collection of facts. Every week adds fresh material to the heap; the science is in danger of being crushed beneath the load of details.

M. M. PATtison MUIR

\section{FIRE RISKS FROM ELECTRIC LIGHTING}

$A$ VERY strong and influential committee was recently A formed by the Society of Electricians to draw up a series of rules and regulations not only for the guidance and instruction of those who have electric lighting apparatus installed on their premises, but for the reduction to 
a minimum of those risks of fire which are inherent to every system of artificial illumination. They point out that the chief dangers of every new application of electricity arise mainly from ignorance and inexperience on the part of those who supply and fit up the requisite plant.

The difficulties that beset the electrical engineer are chiefly internal and invisible, and they can only be effectually guarded against by "testing" or probing with electric currents. They depend chiefly on leakage, undue resistance in the conductor, and bad joints, which lead to waste of energy and the production of heat. These defects can only be detected by measuring, by means of special apparatus, the currents that are either ordinarily or for the purpose of testing, passed through the circuit. Bare or exposed conductors should always be within visual inspection, since the accidental falling on to, or the thoughtless placing of other conducting bodies upon such conductors might lead to "short circuiting" or the sudden generation of heat due to a powerful current of electricity in conductors too small to carry it.

The Committee point out that it cannot be too strongly urged that amongst the chief enemies to be guarded against are the presence of moisture and the use of "earth" as part of the circuit. Moisture leads to loss of current and to the destruction of the conductor by electrolytic corrosion, and the injudicious use of "earth" as a part of the circuit tends to magnify every other source of difficulty and danger.

The chief element of safety is the employment of skilled and experienced electricians to supervise the work.

The rules deal with the installation of the dynamomachine, the fixture of the wires, the character of the lamps to be used, and the danger that accrues to the person.

To secure persons from danger inside buildings, it is essential so to arrange the conductors and fittings, that no one can be exposed to the shocks of alternating currents exceeding 60 volts; and that there should never be a difference of potential of more than 200 volts between any two points in the same room.

If the difference of potential within any house exceeds 200 volts, whether the source of electricity be external or internal, the house should be provided outside with a "switch," so arranged that the supply of electricity can be at once cut off.

The rules are very valuable, and should be obtained by all those who are contemplating the use of the electric light.

\section{PROF. HAECKEL IN CEYLON}

$$
\text { II. }
$$

I the July number of the Deutsche Rundschau, Prof Haeckel gives a further account of his stay in Ceylon, a stay which his ardent enthusiasm and unwearied industry cannot fail to have made fruitful in results to the scientific world. The present series of papers being intended for magazine readers in general, is, as might be expected, altogether popular in tone. The Professor's researches and discoveries in support of the theory of Evolution, are only implied, not described in detail His letter is written from the point of view of an intelligent and cultivated traveller, fully alive to the novelty and beauty of the scenes in which he found himself, and of a naturalist anxious to make the most of his very limited time to become familiar with the fauna and flora of that lovely island which Buddhist poets gracefully apostrophise as "a pearl on the brow of India." The energetic Professor was evidently a subject of much wonder to the languid Anglo-Indians and lazy Singhalese, as, in his white linen suit and "Sola" hat, he braved the mid-day sun and even nccasionally the tropical rains, besides setting at nought the bites of countless leeches and the stings of mosquitoes and scorpions, and prosecuted his researches from morning till night. It is, however, to this constant bodily exercise and to his invariably temperate diet, that Prof. Haeckel ascribes his perfect heaith while on the island; but it is doubtful whether, as the body became enervated by the climate, such habits could be long sustained.

The first, and one of the most delightful excursions made by Prof. Haeckel in Ceylon, consisted in a visit to a Singhalese village called Kaduwella, situated on the left (southern) bank of the Kalany, about ten miles from Colombo. The party from Whist Bungalow, joined by their fellow countrymen residing at the neighbouring Elie House (formerly the residence of Sir J. Emerson Tennent) drove to the appointed place in the little one-horse carriages universal in Ceylon, which are drawn by brisk Burmese ponies, whose speed is superior to their staying powers, ten miles being quite sufficient to tire them out. Horses are rarely used in Ceylon, except in spring carriages, and are almost all imported from the Indian mainland, or from Australia; European horses cannot survive the climate. Bullocks may be said to be the only animals of draught or burden, and Prof. Haeckel mentions the long string of bullock carts, some single, some double, which are constantly met on the road; "the bullocks all belong to the class of the Zebu or humped oxen of India (Bos indicus), but there are many varleties; one of the smaller kinds is very swift and agile." I

Prof. Haeckel notes as among the most beautiful effects of the Ceylonese lowlands through which the road to Kaduwella lies, the middle place which they occupy between garden and forest, between cultivated and uncultivated nature." Surrounded by majestic trees, all overhung and overgrown with creepers and climbers, one might often imagine oneself in the midst of the wildest forest; but a little hut almost hidden beneath a breadfruit tree, a dog or a pig issuing from the brushwood, children playing hide and seek behind the caladium leaves, serve to remind us that we are in fact in a Ceylonese garden. The real forest, on the other hand, which is closely adjacent, with its manifold juxtaposition of every variety of tropical trees, with its orchids, cloves, lilies, malvaceæ, and other lovely flowering plants, shows all the variety and apparent design of a costly pleasure garden. This singular mixture of nature and culture is visible also in the human accessories of these forestgardens; for so great is the simplicity of the dwellings and the clothing of the Singhalese inhabiting them, that although the descendants of an old and cultivated race, there is little in their appearance to distinguish them from mere savages." Arrived at Kaduwella, after a halt and refreshment at the Rest-house (the government substitute for hotels, which are altogether wanting in Ceylon except in the chief towns), Prof. Haeckel made his first attempt to penetrate an Indian jungle, with what success his own words must tell: "The jungle is not, properly speaking, 'primeval forest,' forest, that is, untrodden by the foot of man (such are in Ceylon of small extent and rare occurrence); but it corresponds to our idea of such a forest in that it consists of a dense and impenetrable mass of mighty trees of all kinds, which have sprung up without regularity or any interference from man, and are surrounded and overgrown by a wilderness of creeping and climbing plants, of ferns, orchids, and other parasites, the interstices being so completely filled up with a motley mass of smaller weeds that it is quite impossible to disentangle the coil of tendrils so as to distinguish one species from the other. My first attempt to penetrate such a jungle as this was sufficient to convince me of the impossibility of the undertaking except with the aid of axe and fire. A hard hour's work brought me only a few steps into the thicket

I A pair of these little bullocks carry up about twenty bushels of rice t the hills, and bring down from fifty to sixty , bushels of cuffee to Cclombo (Sir J. E. Tennen's "Nat. Hist. of Ceylon," f. 52 ) 